\title{
OS DESAFIOS DA FORTIFICAÇÃO DE ALIMENTOS
}

\author{
CERES MATTOS DELLA LUCIA* \\ JULIANA FARIAS DE NOVAES** \\ HELENA MARIA PINHEIRO SANT'ANA***
}

\begin{abstract}
Este trabalho teve como objetivo realizar uma revisão sistemática da literatura a respeito da fortificação de alimentos e os principais desafios na obtenção de sucesso em programas de fortificação. Foram abordados os níveis recomendados dos principais micronutrientes utilizados como agentes de fortificação e revisados os aspectos relacionados à adição de ferro, zinco, vitamina $\mathrm{A}$ e ácido fólico aos alimentos. Também foram abordadas as novas tecnologias para o controle das deficiências de micronutrientes e a utilização do arroz como veículo de fortificação, sumarizando-se os principais estudos desenvolvidos sobre o tema. Concluiu-se que a escolha correta dos micronutrientes fortificantes, o estabelecimento dos níveis de fortificação e a seleção do veículo adequado são algumas das questões fundamentais para a obtenção de sucesso nos programas de fortificação.
\end{abstract}

* Nutricionista, Doutoranda em Ciência da Nutrição, Departamento de Nutrição e Saúde, Universidade Federal de Viçosa (UFV), Viçosa, MG (e-mail: ceresnut@yahoo.com.br).

** Nutricionista, Professora Adjunta, Departamento de Nutrição e Saúde, UFV, Viçosa, MG (e-mail: jnovaes@ufv.br).

*** Nutricionista, Professora Associada IV, Departamento de Nutrição e Saúde, UFV, Viçosa, MG (e-mail: helena.santana@ufv.br). 


\section{INTRODUÇÃO}

A deficiência de micronutrientes vem ganhando importância epidemiológica e tem chamado a atenção de profissionais e autoridades de saúde em todo o mundo (FERRAZ, DANELUZZI e VANNUCCHI, 2000). A maior parte dessas deficiências se manifesta de forma subclínica, não apresentando indícios evidentes de enfermidade, razão pela qual vem sendo chamada de fome oculta (DÍAZ, DE LAS CAGIGAS e RODRÍGUEZ, 2003).

Mais de 840 milhões de pessoas não consomem alimentos em quantidades suficientes para suprir suas necessidades diárias básicas de energia. População ainda maior, estimada em três bilhões de pessoas, sofre os efeitos da deficiência de micronutrientes porque não têm acesso a alimentos ricos em vitaminas e minerais, tais como carnes, frutas e hortaliças em quantidade suficiente. Mulheres e crianças da África Subsaariana, da Ásia Meridional, do Sudeste Asiático, da América Latina e do Caribe apresentam maior risco de contrair doenças, de morte prematura e de deterioração de sua capacidade cognitiva por consumirem dietas pobres em micronutrientes essenciais, particularmente ferro, vitamina A, iodo e zinco (NUTTI, CARVALHO e WATANABE, 2011).

Os distúrbios do estado nutricional, em especial os relacionados à deficiência de micronutrientes, podem ter causalidade múltipla. Essas deficiências constituem fatores de risco para a saúde e sobrevivência de grupos vulneráveis, como crianças em idade pré-escolar, gestantes e idosos (MARTINS et al., 2007). A deficiência de minerais e vitaminas pode interferir em todo o desenvolvimento do indivíduo, com consequências tanto sob o ponto de vista físico como social e econômico (NUTTI, CARVALHO e WATANABE, 2011).

A alimentação ideal precisa conter todos os nutrientes de que o ser humano necessita $e$ todas as pessoas deveriam ter acesso à alimentação equilibrada. No entanto, certos nutrientes nem sempre estão disponíveis para a população, ou nem todos podem ter acesso a eles (ZANCUL, 2004).

O objetivo do presente trabalho foi efetuar revisão sistemática da literatura a respeito da fortificação de alimentos e os principais desafios na obtenção de sucesso em programas de fortificação.

\section{MATERIAL E MÉTODOS}

Realizou-se pesquisa bibliográfica retrospectiva das publicações dos últimos 20 anos utilizando as bases de dados Pubmed, Science Direct, Scielo, HighWire Press e periódicos da Capes, além de outras fontes bibliográficas consideradas relevantes. Os descritores utilizados foram: fortificação, biofortificação, ferro, zinco, ácido fólico, vitamina A, deficiência de micronutrientes, arroz fortificado e seus correspondentes em inglês e espanhol.

\section{FORTIFICAÇÃO DE ALIMENTOS}

Devido à industrialização e às mudanças no estilo de vida, verifica-se tendência crescente do consumo de alimentos que conduzem à menor ingestão de micronutrientes (VISIOLI e HAGEN, 2007).

$\mathrm{O}$ alto consumo de produtos industrializados e o baixo consumo de carnes e produtos de origem animal parecem representar uma das maiores razões para o aumento da prevalência de deficiências nutricionais em países em desenvolvimento. Crianças e mulheres em idade fértil são os segmentos mais vulneráveis (RANUM, 2001).

Estimativas sugerem que cerca de 815 milhões de famílias no mundo sofram de deficiência de micronutrientes (UNDERWOOD, 2003). Mesmo no ocidente, determinadas populações podem sofrer de deficiências de micronutrientes, como (1) famílias economicamente desfavorecidas que não possuem recursos para a compra de produtos fortificados; (2) indivíduos com determinados hábitos alimentares (por exemplo, bebês de mães veganas e macrobióticas) (BLACK, 2003), ou indivíduos 
provenientes de populações que vivem em áreas com solos pobres (EICHHOLZER, 2003).

Em geral, as quatro principais estratégias de intervenção em uso para melhorar os níveis de micronutrientes deficientes na dieta são: (1) o aumento da ingestão de alimentos ricos nesses micronutrientes, ou seja, a diversificação alimentar; (2) a administração periódica de doses elevadas desses micronutrientes (suplementação); (3) a fortificação de um ou mais itens alimentares comumente consumidos, e (4) a biofortificação (LEE, HAMER e EITENMILLER, 2000).

A diversificação alimentar envolve o consumo de grande variedade de alimentos para cobrir as necessidades de nutrientes. As comunidades que vivem no mundo em desenvolvimento dependem de fontes específicas de alimentos muitas vezes deficientes em alguns micronutrientes. Em tais condições, parece bastante racional adicionar outros componentes alimentares à dieta visando seu equilíbrio (GRAEBNER et al., 2004). Entretanto, a eficácia dos programas de suplementação depende do nível de cobertura e conformidade. Por exemplo, o suplemento de ferro na forma de cápsulas e xarope não tem sido bem sucedido em países em desenvolvimento (BEINNER e LAMOUNIER, 2003). A suplementação com zinco, por sua vez, tem se mostrado eficaz na redução da morbidade e mortalidade por doenças infecciosas (BROWN et al., 2007).

A fortificação de alimentos é a maneira mais econômica, flexível e socialmente aceitável para melhorar o estado nutricional dos indivíduos nos países em desenvolvimento. A adição de micronutrientes na margarina, no leite e em cereais, por exemplo, tem reduzido consideravelmente a ocorrência de deficiências. Idealmente, os alimentos mais consumidos pela maioria dos segmentos da população devem ser escolhidos como veículos de fortificação (WAHLQVIST, 2008).

A fortificação de alimentos com a adição de vitaminas e minerais tem sido utilizada há bastante tempo (BACKSTRAND, 2000). No mundo industrializado, a fortificação de alimentos processados tem se mostrado eficiente para reduzir os riscos de deficiências de micronutrientes da população em geral (MORA et al., 2000). A fortificação apresenta várias vantagens, mas também encontra dificuldades. Entre as vantagens estão a alta cobertura populacional, o fato de não modificar os hábitos alimentares e de apresentar baixo risco de toxicidade. As dificuldades estão ligadas ao consumo massivo do alimento, sua distribuição e preço (ZANCUL, 2004).

Nos programas de fortificação devem ser consideradas a quantidade consumida do alimento fortificado e a concentração do micronutriente a ser adicionado para que possam alcançar o efeito desejado (DARY e MORA, 2002). A eficiência da fortificação para corrigir, erradicar ou prevenir doenças específicas causadas por deficiências de nutrientes, é amplamente reconhecida. No entanto, os programas de fortificação devem ser colocados em prática juntamente com outras ações que levem a combater ou a evitar outros problemas nutricionais, mediante alimentação composta por alimentos em seu estado natural (TORÚN, 1988).

Existem certos passos a serem seguidos para que o programa de fortificação de alimentos alcance bons resultados. Deve-se determinar a prevalência da deficiência do micronutriente, conseguir o suporte da indústria de alimentos e usar compostos com alta biodisponibilidade. É muito importante a seleção correta do tipo de composto a ser utilizado na fortificação, assim como do veículo de transporte, já que os alimentos podem interferir na absorção dos elementos, diminuindo sua biodisponibilidade (SALGUERIO et al., 2002). Além disso, a quantidade de micronutrientes a ser adicionada nos alimentos não deve ultrapassar o valor determinado pela Recommended Dietary Allowance (RDA) para que não provoque efeitos colaterais nas pessoas e não mude as características do produto (ZANCUL, 2004). Outro fator muito importante a ser considerado para o sucesso dos programas de fortificação refere-se a alterações físico-químicas que podem ocorrer tanto no veículo de fortificação quanto no produto final, as quais precisam ser cuidadosamente monitoradas. A fortificação de produtos derivados de cereais, como é o caso da farinha de trigo integral, com novas fontes de ferro e zinco vem ganhando popularidade para superar a deficiência de micronutrientes nos países em desenvolvimento (AKHTAR, ANJUM e ANJUM, 2011). 


\subsection{NÍVEIS DE FORTIFICAÇÃO RECOMENDADOS}

A seleção e os níveis adequados do agente de fortificação representam os fatores mais importantes a serem levados em consideração. Por exemplo, a fortificação da farinha de trigo utilizando níveis adequados das formas mais biodisponíveis de ferro pode promover melhora do estado nutricional de ferro com risco muito menor de efeitos adversos. Estudos de eficácia indicam que o consumo diário de $7,1 \mathrm{mg}$ de sulfato ferroso (equivalente a 7,1 $\mathrm{mg}$ de fumarato férrico ou $10 \mathrm{mg}$ de ferro eletrolítico), mediante produtos elaborados com farinha fortificada melhora o estado nutricional de ferro em mulheres em idade fértil (FFI, 2008). O nível de adição de ferro nos alimentos provenientes de cereais (farinha de trigo, farinha de milho e arroz branco) deve abranger de $25 \mathrm{ppm}$ a 80 ppm, dependendo da necessidade de ferro adicional e do consumo de cereal pela população (RANUM, 1999).

A farinha pode ser fortificada com pelo menos $100 \mathrm{mg}$ de zinco/kg sem efeitos adversos sobre as propriedades sensoriais e aceitabilidade dos produtos fortificados (ARREDONDO et al., 2006). Ranum (2001) demonstrou que mesmo menores níveis de adição de zinco, em torno de 20 30 ppm, seriam benéficos para auxiliar o atendimento ds recomendações nutricionais. Afirmou que o consumo diário de $100 \mathrm{~g}$ de cereais enriquecidos com 20 ppm de zinco é capaz de atender 20\% das necessidades diárias de zinco para crianças.

\subsection{O FERRO COMO AGENTE DE FORTIFICAÇÃO}

A fortificação difere para cada micronutriente, sendo particularmente difícil para o ferro devido à sua rápida oxidação (BOCCIO e IYENGAR, 2003). Mesmo o encapsulamento do ferro para reduzir a oxidação não tem trazido bons resultados, ocorrendo aumento da perda de iodo (WEGMÜLLER, ZIMMERMANN e HURRELL, 2003). Os problemas associados à dificuldade da utilização do ferro como agente de fortificação levaram à proposição de sugestões exóticas, como cozinhar alimentos em panelas de ferro (PRINSEN, BRABIN e OMARI, 2003) ou a adição de ferro elementar à dieta (SWAIN, NEWMAN e HUNT, 2003), mas o sucesso de tais abordagens ainda é questionável e não comprovado.

Para que programas de fortificação com ferro sejam bem-sucedidos é necessário incluir o uso de formas solúveis de ferro, tais como o sulfato ferroso, adição de ácido ascórbico como promotor da absorção ou a utilização de NaFeEDTA para superar os efeitos negativos do ácido fítico (AKHTAR et al., 2010). O ácido etileno diamino tetracético (EDTA), quelante capaz de se combinar com praticamente todos os minerais, tem sido utilizado em associação ao ferro e ao cálcio para aumentar a biodisponibilidade desses minerais (AKHTAR, ANJUM e ANJUM, 2011).

O NaFeEDTA, o sulfato ferroso e o fumarato ferroso são os agentes de fortificação preferidos para as farinhas de trigo e milho. A eficácia de NaFeEDTA para melhorar o estado nutricional de ferro tem sido demonstrada em diversos estudos. Quando misturado com alimentos em diversos níveis de fortificação, o ferro contido no NaFeEDTA apresenta melhor absorção do que outras formas de ferro não-heme. Além disso, ele não é sensível aos inibidores de ferro contidos em muitos alimentos. Esse composto torna-se interessante principalmente para populações que se alimentam basicamente de cereais ou leguminosas, devido à sua melhor capacidade de absorção e estabilidade química (não sofre rancificação). Portanto, é adequado para uso como agente de fortificação na farinha de trigo (VITERI et al., 1995).

A preocupação suscitada quanto ao consumo de NaFeEDTA parte do princípio de que os níveis dietéticos de EDTA são elevados nos países desenvolvidos, devido a sua utilização como conservante. No entanto, a ingestão diária aceitável (IDA) de EDTA é de $150 \mathrm{mg} / \mathrm{pessoa} / \mathrm{dia}$ ou 2,5 mg/kg/dia. Dados de 1992 mostram que a média geral de exposição ao EDTA nos Estados Unidos da América (EUA) foi de $15 \mathrm{mg} /$ pessoa/dia, sugerindo que o uso de NaFeEDTA como agente de fortificação pode ser possível nos EUA e, especialmente, nos países em desenvolvimento com consumo habitual mais baixo (INACG, 1993). 
A bibliografia sobre o tema revela que muitos problemas de deficiência de ferro já foram reduzidos com a fortificação. No Brasil, a deficiência de ferro e a anemia ferropriva são prevalentes, afetando mais de $50 \%$ das crianças de seis a vinte e quatro meses de idade, principalmente em regiões pobres, e a fortificação de alimentos tem sido usada com sucesso. Em Ribeirão Preto (SP) foi realizado trabalho com adição de ferro na água potável oferecida nas creches a crianças em idade pré-escolar, que conduziu a resultados muito promissores após oito meses. As concentrações de hemoglobina e ferritina aumentaram significativamente nas crianças já nos primeiros quatro meses de intervenção (DUTRA DE OLIVEIRA e MARCHINI, 1996). Outro trabalho, realizado no município de Angatuba (SP), comprovou a eficácia da fortificação do leite fluido com $3 \mathrm{mg}$ de ferro aminoácido quelato no combate à carência de ferro em crianças menores de quatro anos. Foram acompanhadas duzentos e sessenta e nove crianças que receberam, por dia, durante doze meses, um litro de leite fortificado. A anemia que estava presente em $62,3 \%$ das crianças antes do início do trabalho foi reduzida para $26,5 \%$ das crianças no final de doze meses, mostrando a viabilidade e a eficácia da fortificação do leite fluido como medida de intervenção no combate à carência de ferro em pré-escolares (TORRES et al., 1996).

No Chile, leite fortificado com $15 \mathrm{mg} / \mathrm{L}$ de sulfato ferroso foi ministrado a duzentos e setenta e seis crianças com mais de três meses de idade. Essas crianças foram comparadas com duzentos e setenta e oito crianças que receberam leite não fortificado. Após quinze meses de intervenção, $25,7 \%$ das crianças que receberam leite não fortificado tinham anemia contra apenas $2,5 \%$ que continuaram anêmicas após receberem leite fortificado (OLIVARES, 1989).

\subsection{ZINCO COMO AGENTE DE FORTIFICAÇÃO}

Sérias preocupações surgem com a necessidade de se fortificar alimentos com zinco, especialmente nas populações de países em desenvolvimento, cujas dietas contêm fatores antinutricionais limitantes da biodisponibilidade desse micronutriente.

Vários sais de zinco estão disponíveis para a fortificação de alimentos. Esses sais variam em solubilidade de muito solúveis (sulfato e cloreto), levemente solúveis (acetato) a quase insolúveis (carbonatos e óxidos) (HENDERSON et al., 1995). O óxido de zinco constitui a fonte mais comumente utilizada para a fortificação de alimentos à base de cereais, seguido pelo sulfato de zinco e, em menor extensão, pelo gluconato de zinco.

Compostos menos sensíveis à oxidação são mais fáceis de serem utilizados na fortificação de alimentos. Por exemplo, Rosado (2003) relatou esforços bem sucedidos para fortificar a farinha de trigo com óxido de zinco (20-50 mg/kg) e gluconato de cobre (1,2-3,0 mg/kg). No entanto, a fortificação com gluconato de cobre parece ser desnecessária, pois os grãos de cereais integrais também representam fonte rica de cobre e, portanto, devem ter seu consumo estimulado (STANNER, 2003).

\subsection{VITAMINA A COMO AGENTE DE FORTIFICAÇÃO}

As formas comerciais mais importantes de vitamina A são retinil acetato e retinil palmitato. Essas substâncias químicas em sua forma purificada têm sido adicionadas aos alimentos, principalmente como corantes. No entanto, os alimentos também podem carreá-los visando aumentar o consumo de vitamina A das populações (LOTFI et al., 1996).

Estudo, realizado com a população urbana pobre da Guatemala, mostrou a fortificação de alimentos como importante contribuição para o aumento geral da ingestão de vitamina A (KRAUSE, DELISLE e SOLOMONS, 1998).

Da mesma maneira que são necessários certos cuidados na escolha de alimentos para fortificação com ferro (devido mudanças que podem ocorrer nas suas características e na biodisponibilidade do micronutriente), assim também é necessária a seleção de compostos e de alimentos adequados a serem usados como veículos na fortificação com vitamina A (ZANCUL, 2004). 
O uso de óleo vegetal fortificado com vitamina A constitui técnica simples e de baixo custo. No Brasil, a vitamina A adicionada ao óleo usado na alimentação básica para cozimento de arroz mostrou significativo aumento das reservas dessa vitamina no fígado das pessoas alvo do estudo (DARY e MORA, 2002). Outra pesquisa mostrou a viabilidade do uso de óleos vegetais, como o óleo de soja, na fortificação com vitamina A. O estudo comprovou a estabilidade da vitamina A adicionada ao óleo de soja durante o cozimento dos alimentos. No cozimento do arroz foram conservados $99 \%$ da vitamina A adicionada ao óleo de soja e no feijão, fervido por aproximadamente 90 minutos, houve preservação de $88 \%$ da vitamina A. Quando o feijão foi cozido em panela de pressão por 40 minutos, 90\% da vitamina A foi conservada (FÁVARO et al., 1991).

\section{5 ÁCIDO FÓLICO COMO AGENTE DE FORTIFICAÇÃO}

O desafio em relação à fortificação com ácido fólico envolve sua alta solubilidade em água que dificulta sua manutenção, por exemplo, em grãos de arroz durante a ebulição. Nos casos em que os cereais não podem ser fortificados tem-se como alternativa a adição desse micronutriente ao leite de vaca, o qual pode ser misturado com cereais pré-cozidos (SHRESTHA, ARCOT e PATERSON, 2003).

Estudos destacaram a importância do ácido fólico na prevenção dos defeitos do tubo neural (DTN), apesar do seu mecanismo de ação ainda ser pouco compreendido (BOYLES et al., 2003). Indicações de redução, em torno de $50 \%$ a $70 \%$, na ocorrência de tais defeitos congênitos após a suplementação periconcepcional desse nutriente têm feito com que várias organizações de saúde recomendem a sua utilização (IOM, 1998). O Centers for Diseases Control and Prevention (CDC), em 1992, recomendou a administração diária (três meses antes da concepção até o primeiro trimestre da gestação) de $0,4 \mathrm{mg}$ de ácido fólico a mulheres em idade fértil para a prevenção da primeira ocorrência de DTN e de $4 \mathrm{mg}$ para a redução do risco de recorrência (IOM, 1998). O Institute of Medicine (IOM) estabeleceu nos Estados Unidos, em 2000, a dose de 0,4 mg/dia para mulheres adultas não gestantes e de $0,6 \mathrm{mg} /$ dia para gestantes (IOM, 1998). No Brasil, a Agência Nacional de Vigilância Sanitária (ANVISA) elevou as recomendações nutricionais de ingestão diária de ácido fólico conforme proposto pelo IOM (PACHECO et al., 2009).

Visando garantir ampla cobertura da estratégia de suplementação de ácido fólico à população de gestantes, 40 países instituíram a medida da fortificação de alimentos consumidos em larga escala com ácido fólico para a prevenção da ocorrência de DTN (SANTOS e PEREIRA, 2007). Pesquisa realizada em 45 estados dos EUA (HONEIN et al., 2001) constatou redução de $19 \%$ na ocorrência de defeitos de fechamento do tubo neural após a implantação da medida. Na llha de Newfoundland, Canadá, foi observada redução de $78 \%$ na prevalência de DTN após o período mandatório de fortificação com ácido fólico (LIU et al., 2004).

A ANVISA, atendendo a recomendação da Organização Pan-Americana da Saúde (OPAS), tornou obrigatória a fortificação das farinhas de trigo e de milho com $150 \mu \mathrm{g} / 100 \mathrm{~g}$ de ácido fólico à partir de junho de 2004 (SANTOS e PEREIRA, 2007). No entanto, não foram encontrados estudos avaliando a efetividade dessa medida sobre a prevalência de DTN no Brasil.

\section{O USO DE NOVAS TECNOLOGIAS: O ARROZ COMO VEÍCULO DE FORTIFICAÇÃO}

Vários alimentos, incluindo o açúcar (ARROYAVE, MEJIA e AGUILAR, 1981), a soja (FAVARO et al., 1991), o leite (HURREL, 1997), o óleo, a farinha e o arroz (MURPHY et al., 1992) têm sido explorados como potenciais veículos para a fortificação. Entre eles, o arroz tornou-se o candidato ideal para a fortificação por ser alimento básico nos países em que deficiências específicas atingem altas prevalências (HURREL, 1997). O arroz ocupa posição de destaque no celeiro mundial como o cereal mais consumido entre os povos, sendo superado em produção apenas pelo trigo, o que demonstra seu alcance como veículo de fortificação (PESTANA, MENDONÇA e ZAMBIAZI, 2008). 
Tentativas envolvendo a fortificação da farinha de arroz foram mal-sucedidas, devido ao hábito de lavar o arroz que resulta na lixiviação do componente utilizado para enriquecimento (HOFFPAUER, 1992). Entretanto, foi criada tecnologia que superou essa barreira. Grãos quebrados e trincados, que geralmente compreendem de $20 \%$ a $30 \%$ da colheita e são desviados para fins de alimentação animal ou fabricação de cerveja, podem ser transformados em farinha de arroz e combinados com aglutinante e outros nutrientes fortificantes. Ao ser remodelado em grãos de arroz apresenta o mesmo tamanho, forma e textura do arroz convencional. Os níveis dos agentes de fortificação podem ser concentrados nos grãos a serem misturados com o arroz convencional na proporção de 1:100 a 1:200. O produto final obtido pode fornecer $100 \%$ das necessidades diárias dos micronutrientes para crianças que consomem a quantidade diária típica de arroz (LEE, HAMER e EITENMILLER, 2000).

A tecnologia Ultra Rice ${ }^{\circledR}$ (UR) de fortificação foi desenvolvida no final de 1980, por James Cox e Duffy Cox, em Lynden, Washington. Desde essa época, modificações na formulação e no processo de fabricação foram realizadas para tornar o produto mais semelhante ao arroz convencional, melhorar suas características sensoriais e aumentar sua capacidade de carrear maior variedade de fortificantes. Em 1997, a patente do UR ${ }^{\circledast}$ com vitaminas foi doada para o Program for Appropriate Technology in Health (PATH, 1999). A maioria dos países não consegue fornecer de forma universalizada o acesso ao alimento ou, em escala mais avançada, o acesso à dieta balanceada. Assim, o PATH vem sendo trabalhado em conjunto com diversas universidades, agências internacionais e também com a iniciativa privada para o desenvolvimento de tecnologia capaz de fornecer de modo simples, viável e economicamente acessível a estratégia para minimizar ou mesmo eliminar a questão das deficiências de micronutrientes ao redor do mundo (PATH, 1999).

Estudo clínico com crianças em idade escolar, no Brasil, confirmou a eficácia do UR ${ }^{\circledR}$ na melhoria dos níveis de retinol sérico (FLORES et al., 1994). Outro estudo, na Indonésia, demonstrou a viabilidade da mistura do $\mathrm{UR}^{\circledR}$ em pequenos engenhos rurais e mostrou excelente aceitação de mercado do produto fortificado resultante (PATH, 1999). Em outro trabalho, realizado na Venezuela, Garcia-Casal et al. (1998) relataram que a presença de vitamina $A$ no trigo, no milho e no arroz aumentou a absorção do ferro não-heme, sugerindo que a vitamina $A$ impediu o efeito inibitório de fitatos sobre a absorção de ferro na dieta.

Pesquisa efetuada na Índia, com duração de sete meses, envolveu crianças em idade escolar e o uso do $U R^{\circledR}$ fortificado com ferro. Foram verificados efeitos positivos nos níveis de ferritina sérica (FS), mas não nos níveis de hemoglobina ( $\mathrm{Hb})$. Embora, as crianças tenham sido desparasitadas antes e durante o ensaio, os autores sugeriram que a inexistência de impacto nos níveis de $\mathrm{Hb}$ pode estar relacionada a infecções endêmicas e carências generalizadas de micronutrientes (MORETTI et al., 2006).

Em trabalho realizado na região metropolitana de Belo Horizonte, com duração de 5 meses, $U^{\circledR}{ }^{\circledR}$ com pirofosfato férrico micronizado e solução placebo foram administrados a grupo de crianças com anemia leve e idades entre 6 e 24 meses $(n=175)$, num esquema duplo cego e aleatório. Outro grupo recebeu arroz não fortificado e suplemento de ferro administrado via oral sob a forma de gotas. A dosagem das concentrações de ferritina sérica (FS) e de hemoglobina ( $\mathrm{Hb})$ foi efetuada na data do início do estudo e ao final dos 5 meses. Na fase inicial, a prevalência de deficiência de ferro e de anemia na amostra total foi de $100 \%$ e $73,1 \%$, respectivamente. Ao final dos 5 meses, as concentrações de FS e de $\mathrm{Hb}$ aumentaram em ambos os grupos, embora a alteração no grupo alimentado com $U R^{\circledast}$ tenha sido estatisticamente superior. O UR ${ }^{\circledR}$ com pirofosfato férrico micronizado aumentou as reservas de ferro e reduziu a incidência de anemia no grupo de crianças com anemia leve e idade entre 6 e 24 meses (PESSOA, 2009).

A Tabela 1 demonstra o delineamento e os principais achados de outros estudos que tiveram como objetivo avaliar a estabilidade de micronutrientes no $U^{\circledR}{ }^{\circledR}$ e seu impacto no estado nutricional de grupos específicos da população. 


\begin{tabular}{|c|c|c|}
\hline 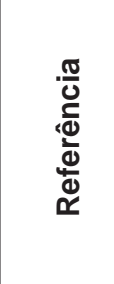 & 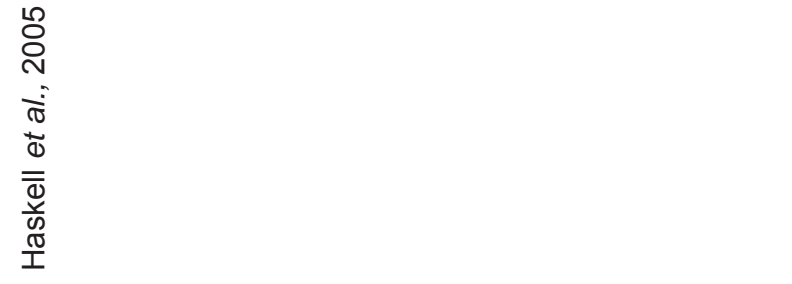 & 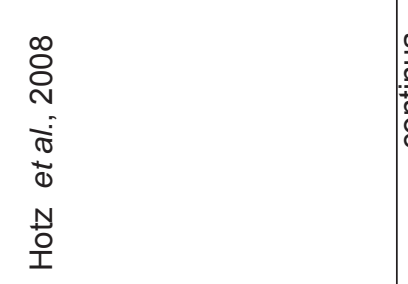 \\
\hline 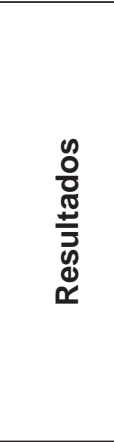 & 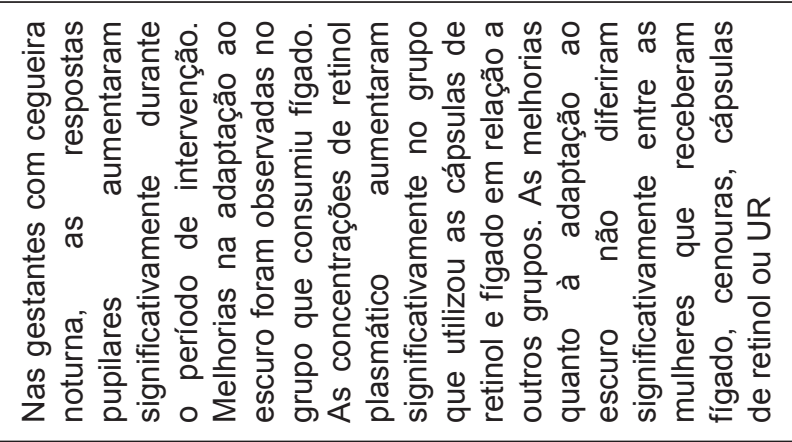 & 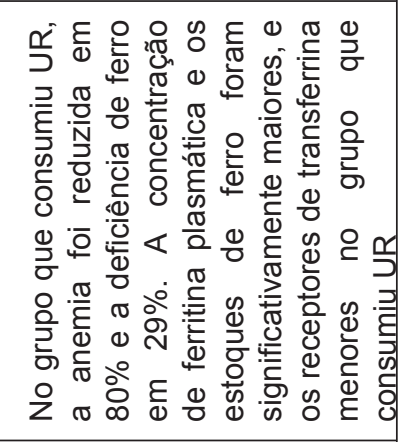 \\
\hline 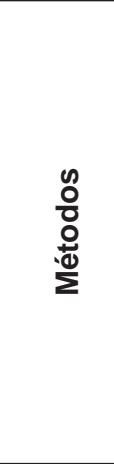 & 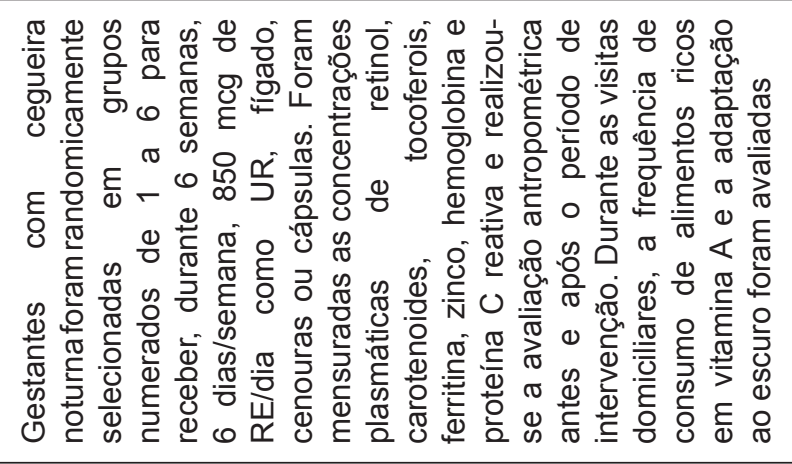 & 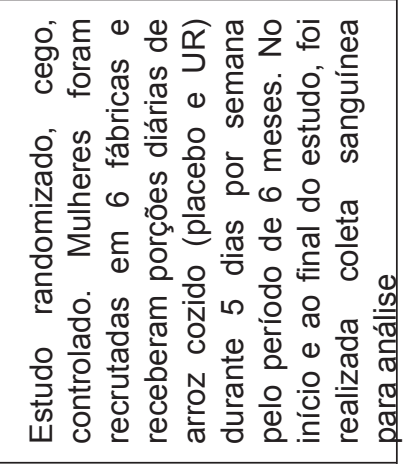 \\
\hline 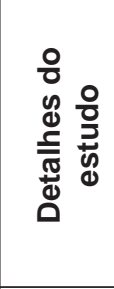 & 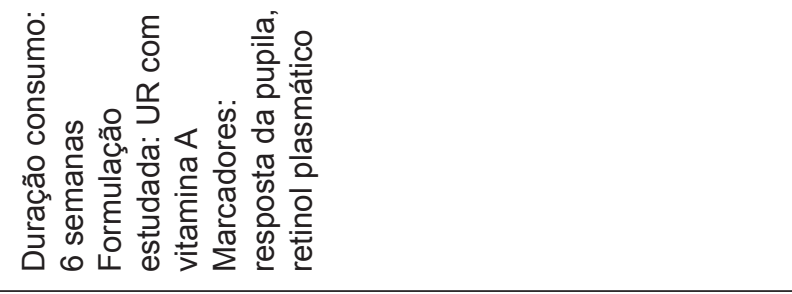 & 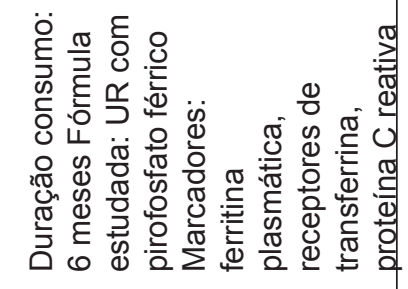 \\
\hline 惫 & 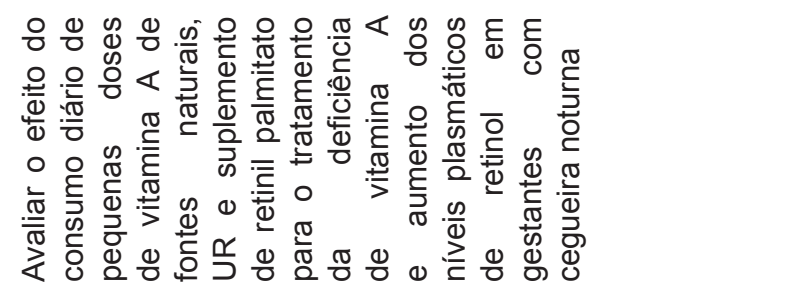 & 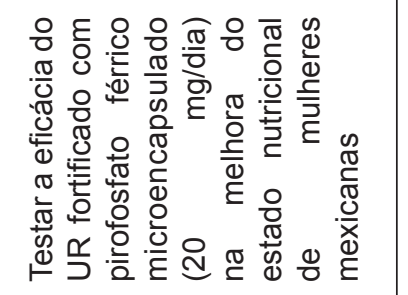 \\
\hline 产怤 & 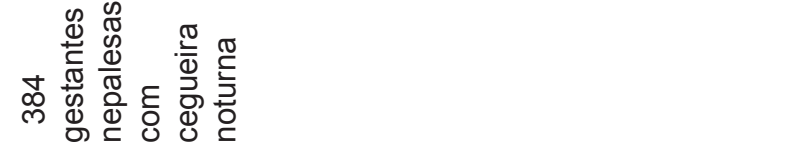 & 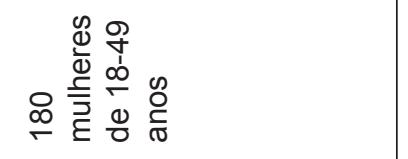 \\
\hline$\frac{\bar{w}}{\frac{5}{0}} \frac{8}{2}$ & 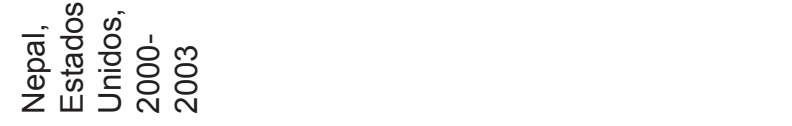 & 离 \\
\hline 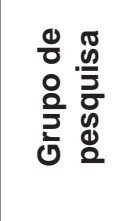 & 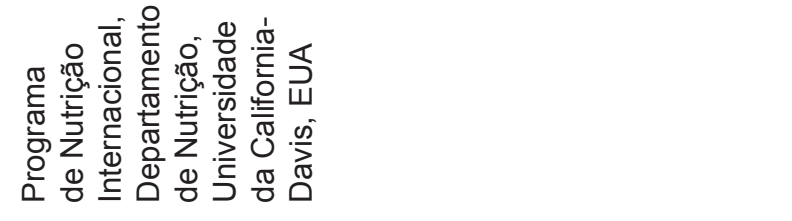 & 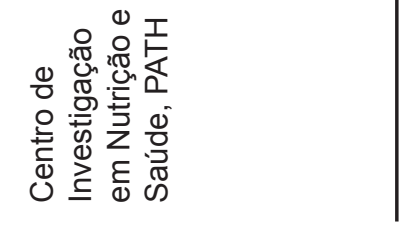 \\
\hline
\end{tabular}




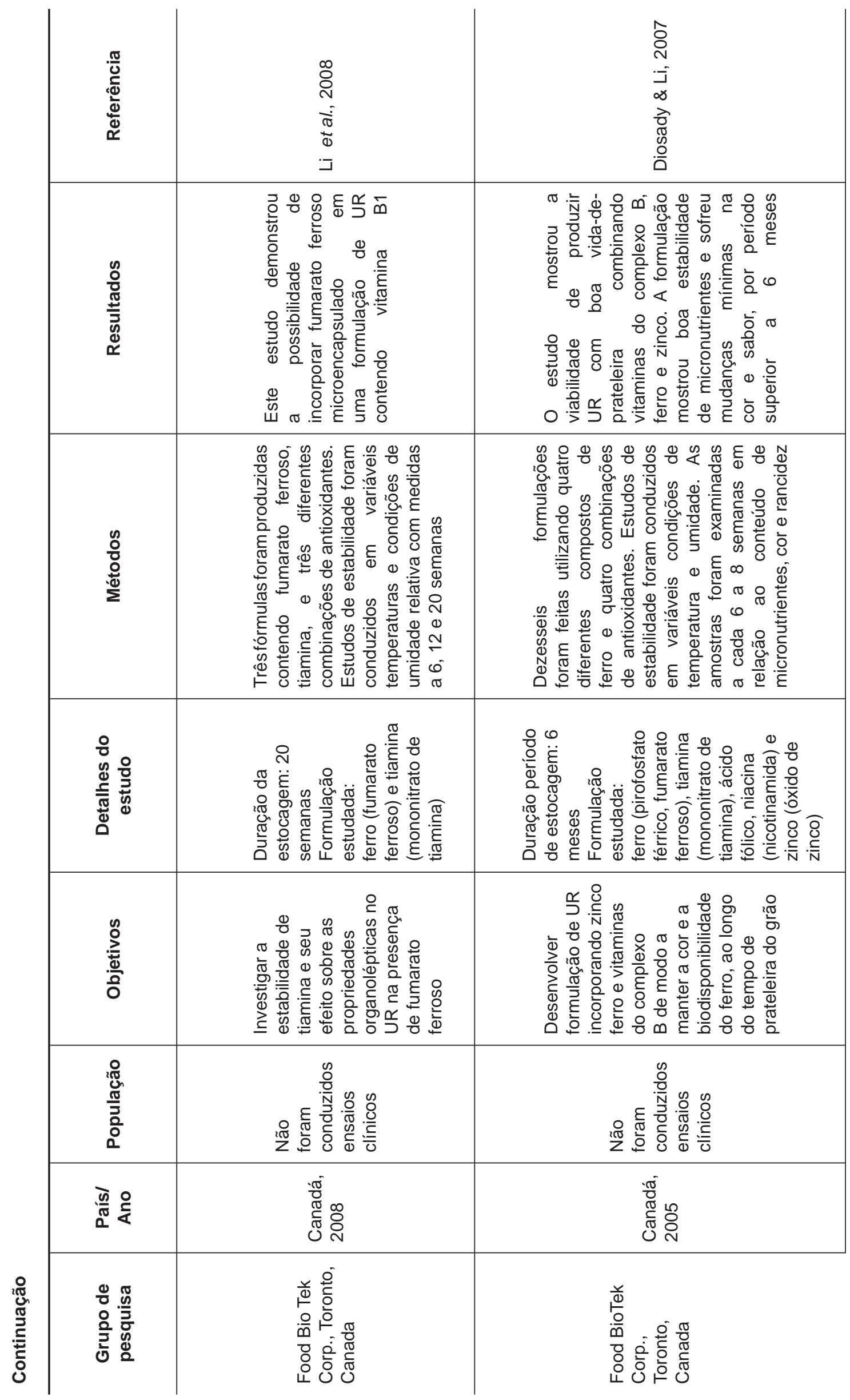




\section{CONCLUSÃO}

As deficiências de micronutrientes podem trazer sérias consequências à saúde e economia mundiais, especialmente em países em desenvolvimento. Embora a erradicação da deficiência de micronutrientes sempre tenha sido prioridade na agenda das organizações internacionais, esse problema ainda persiste. A estimativa correta da prevalência de deficiência de micronutrientes, a implementação de políticas de decisão, a escolha de micronutrientes fortificantes, o estabelecimento dos níveis de fortificação e a seleção do veículo adequado são algumas das questões fundamentais para a obtenção de sucesso nos programas de fortificação.

\section{ABSTRACT}

\section{THE CHALLENGES OF FOOD FORTIFICATION}

This study aimed to perform a systematic literature review about food fortification and the main challenges in achieving success in fortification programs. This article has discussed the recommended levels of the main micronutrients used as agents of fortification and reviewed aspects related to the addition of iron, zinc, vitamin A and folic acid to foods. New technologies in controlling micronutrients deficiencies and the use of rice as a vehicle for fortification were also approached, summarizing the major studies conducted about this subject. It was concluded that the correct choice of the fortifying micronutrients, the establishment of fortification levels and the selection of suitable vehicle are some of the key issues for achieving success on food fortification programs.

KEY-WORDS: MICRONUTRIENT DEFICIENCIES, IRON, ZINC, FOLIC ACID, VITAMIN A, FORTIFIED RICE.

\section{REFERÊNCIAS}

1 AKHTAR, S.; ANJUM, F.M.; ANJUM, M.A. Micronutrient fortification of wheat flour: recent development and strategies. Food Research International, v.44, p.652-659, 2011.

2 AKHTAR, S.; REHMAN, Z.U.; ANJUM, F.M.; ALI, Z.; NISAR, A. Bioavailability of iron and zinc fortified whole wheat flour in rats. Pakistan Journal of Zoology, v.43, p.771-779, 2010.

3 ARREDONDO, M. et al. Inhibition of iron and copper uptake by iron, copper and zinc. Biol. Research, v.39, p.95-102, 2006.

4 ARROYAVE, G.; MEJIA, L.A.; AGUILAR, J.R. The effect of vitamin A fortification of sugar on the serum vitamin A levels of preschool Guatemalan children: a longitudinal evaluation. American Journal of Clinical Nutrition, v.34, p.41-49, 1981.

5 BACKSTRAND, J.R. The history and future of food fortification in the United Sates: a public health perspective. Nutrition Research, v.60, p.15-26, 2002.

6 BEINNER, M.A.; LAMOUNIER, J.A. Recent experience with fortification of foods and beverages with iron for the control of iron-deficiency anemia in Brazilian children. Food and Nutrition Bulletin, v.24, n.3, p.268-274, 2003.

7 BLACK, M.M. Micronutrient deficiencies and cognitive functioning. Journal of Nutrition, v.133, p.3927S-3931S, 2003.

8 BOCCIO, J.R.; IYENGAR, V. Iron deficiency: causes, consequences and strategies to overcome this nutritional problem. Biology Trace Element Research, v.94, p.1-31, 2003.

9 BOYLES, A.B. et al. Neural tube defects and folate pathway genes: family-based association tests of gene-gene and gene-environment interactions. Environmental Health Perspectives, v.114, n.10, p.1547-52, 2006.

10 BROWN, K.H.; WESSELLS, K.R.; HESS, S.Y. Zinc bioavailability from zinc-fortified foods. International Journal for Vitamin and Nutrition Research, v.77, p.174-181, 2007.

11 DARY, O; MORA, J.O. Food fortification to reduce vitamin A deficiency. International Vitamin A Consultative Group Recommendations. Journal of Nutrition, v.132, p.2927S -2933S, 2002.

12 DÍAZ, J.R.; DE LAS CAGIGAS, A.; RODRÍGUEZ, R. Micronutrient deficiencies in developing and affluent countries. European Journal of Clinical Nutrition, v.57, S70-72, 2003.

13 DIOSADY, L.; LI; O.Y. Final report on phase II report on the development and stability testing of an iron-containing formulation of Ultra Rice. International Journal of Food Science and Technology. Disponível em: <http://agfacs. tnstate.edu/uno/Resumes/Olive_Li_CV_TSU.pdf>. Acesso em: 30 maio 2011.

14 DUTRA-DE-OLIVEIRA, J.E.; MARCHINI, J.S. Fortification of drinking water with iron: a new strategy for combating iron deficiency in Brazil. American Journal of Clinical Nutrition, v.63, p.612-614, 1996. 
15 EICHHOLZER M. Micronutrient deficiencies in Switzerland: causes and consequences. Journal of Food Engineering, v.56, p.171-179, 2003.

16 FAVARO, R.M.D. et al. Studies on fortification of refined soybean oil with all-trans-retinyl palmitate in Brazil: stability during cooking and storage. Journal of Food Composition and Analysis, v.4, p.237-244, 1991.

17 FERRAZ, I.S.; DANELUZZI, J.C.; VANNUCCHI, H. Vitamin A deficiency in children age 6 to 24 months in São Paulo State, Brazil. Nutrition Research, v.20, p.757-768, 2000

$18 \mathrm{FFI}$. Flour Fortification Initiative. Second technical workshop on wheat flour fortification: practical recommendations for National Application Summary Report. Stone Mountain, Georgia, USA, 2008.

19 FLORES, H. et al. Efficacy of vitamin A enriched rice in the treatment and prevention of vitamin A deficiency. Recife: Department of Nutrition, Center of Health Science, Federal University of Pernambuco, Brazil, 1994. (Unpublished report).

20 GARCIA-CASAL, M.N. et al. Vitamin A and $\beta$-carotene can improve non-heme iron absorption from rice, wheat and corn by humans. Journal of Nutrition, v.128, p.646-650, 1998.

21 GRAEBNER, I.T.; SIQUEIRA, E.M.A.; ARRUDA, S.F.; DE SOUZA, E.M.T. Carotenoids from native Brazilian dark green vegetables are bioavailable: a study in rats. Nutrition Research Reviews, v.24, p.671-679, 2004.

22 HASKELL, M.J.; PANDEY, P.; GRAHAM, J.M.; SHRESTHA, R.K.; BROWN, K.H. Recovery from impaired dark adaptation in nightblind pregnant Nepali women who receive small daily doses of vitamin A as amaranth leaves, carrots, goat liver, vitamin A-fortified rice or retinyl palmitate. American Journal of Clinical Nutrition, v.81, p. 461-471, 2005.

23 HENDERSON, L.M. et al. Effect of intragastric $\mathrm{pH}$ on the absorption of oral zinc acetate and zinc oxide in the young health volunteers. Journal of Parenteral and Enteral Nutrition, v.19, p.393-397, 1995.

24 HOFFPAUER, D.W. Rice enrichment for today. Cereal Foods World, v.37, p.757-759, 1992.

25 HONEIN, M.A. et al. Impact of folic acid fortification of the US food supply on the occurrence of neural tube defects. Journal of the American Medical Association, v.285, n.23, p. 2981-2986, 2001.

26 HOTZ, C.; PORCAYO, M.; ONOFRE, G.; GARCIA-GUERRA, A.; ELLIOTT, T.; JANKOWSKI, S.; GREINER, T. Efficacy of iron fortified Ultra Rice in improving the iron status of women in Mexico. Food and Nutrition Bulletin, v.29, n.2, p.140-149, 2008.

27 HURRELL, R.F. Preventing iron deficiency through food fortification. Nutrition Review, v.55, p.210-222, 1997.

28 INACG. International Nutritional Anaemia Consultative Group. Iron EDTA for food fortification. Washington DC: The Nutrition Foundation/ILSI, 1993.

29 IOM. Institute of Medicine. Food and Nutrition Board. Folic acid - dietary reference intakes: Thiamin, Riboflavin, Niacin, Vitamin B6, Vitamin B12, Pantothenic Acid, Biotin, and Choline. Washington: National Academy Press, 1998. p.193-305.

30 KRAUSE, M.V.; DELISLE, H.; SOLOMONS, N.W. Fortified foods contribute one half of recommended vitamin A intake poor urban Guatemalan toddlers. Journal of Nutrition, v. 128, p. 860-864, 1998.

31 LEE, J.; HAMER, M.L.; EITENMILLER, R.R. Stability of retinyl palmitate during cooking and storage in rice fortified with ultra rice fortification technology. Journal of Food Science, v.65, n.5, p.915-919, 2000.

32 LI, Y.; DIOSADY, L.; JANKOWSKI, S. Stability of vitamin B1 in Ultra Rice in the presence of encapsulated ferrous fumarate. International Journal of Food Sciences and Nutrition, v.59, n.1, p.24-33, 2008.

33 LIU, S. et al. A comprehensive evaluation of food fortification with folic acid for the primary prevention of neural tube defects. BMC Pregnancy Childbirth, v.4, n.20, p. 1-10, 2004.

34 LOTFI, M.; MANNAR, M.G.V.; MERX, R.H.; HEUVEL, P. Micronutrient fortification of foods: current practices, research and opportunities. The Micronutrient Initiative, Ottawa, International Agriculture Centre, Wageningen. 1996. Disponível em: <http://idl-bnc.idrc.ca/dspace/bitstream/10625/14002/1/104386.pdf>. Acesso em: 04 dez. 2012.

35 MARTINS, M.C.; OLIVEIRA, Y.P.; COITINHO, D.C.; SANTOS, L.M.P. Panorama das ações de controle da deficiência de vitamina A no Brasil. Revista de Nutrição, v.20, n.1, p.5-18, 2007.

36 MEHANSHO, H.; MANNAR, M.G.V. Mineral fortification in developing countries. In: HURRELL, R. (Ed.). The mineral fortification of foods. Leatherhead, UK: Leatherhead Pub., 1999. p. 213-214.

37 MORA, J.O.; DARY, O.; CHINCHILLA, D.; ARROYAVE, G. Fortificación del azúcar con Vitamina A en Centro América: experiencia y lecciones aprendidas. MOST, The USAID Micronutrient Program, Arlington, USA, 2000. Disponível em: <http://www.a2zproject.org/ a2zorg/pdf/sugarlessonsSpanish.pdf>. Acesso em: 04 dez. 2012.

38 MORETTI, D.; ZIMMERMANN, M.B.; MUTHAYYA, S.; THANKACHAN, P.; LEE T.C.; KURPAD, A.V.; HURRELL, R.F. Extruded rice fortified with micronized ground ferric pyrophosphate reduces iron deficiency in India schoolchildren: a double-blind randomized controlled trial. American Journal of Clinical Nutrition, v.84, p.822-829, 2006. 
39 MURPHY, P.A.; SMITH, B.; HAUCK, C.; O'CONNOR, K. Stabilization of vitamin A in a synthetic rice premix. Journal of Food Science, v.57, p.437-439, 1992.

40 NUTTI, M.; CARVALHO, J.L.V.; WATANABE, E. A biofortificação como ferramenta para combater a deficiências em micronutrientes. Disponível em: <http://www.cprm.gov.br/publique/media/geo_med7.pdf>. Acesso em: 12 maio 2011.

41 OLIVARES, M.; WALTER, T.; HERTRAMPF, E.; PIZARRO, F.; STEKEL, A. Prevention of iron deficiency by milk fortification. Acta Paediatric Scandinavica, v. 361, p.109-113, 1989.

42 PACHECO, S.S.; BRAGA, C.; SOUZA, A.I.; FIGUEIROA, J.N. Efeito da fortificação alimentar com ácido fólico na prevalência de defeitos do tubo neural. Revista de Saúde Pública, v.43, n.4, p.564-571, 2009.

43 PATH. Program for Appropriate Technology in Health. Seattle, Wa., 1999. Personal communication. Disponível em: <http:// www.path.org/>. Acesso em: 04 dez. 2012.

44 PESSOA, M.C. Eficácia do consumo de arroz fortificado com ferro no tratamento de crianças com anemia carencial. 2009. 64 f. Dissertação (Mestrado em Saúde e Enfermagem) - Escola de Enfermagem, Universidade Federal de Minas Gerais, Belo Horizonte, 2009.

45 PESTANA, V.R.; MENDONÇA, C.R.B.; ZAMBIAZI, R.C. Farelo de arroz: características, benefícios à saúde e aplicações. Boletim do CEPPA, v.26, n.1, p.29-40, 2008.

46 PRINSEN, G.P.D.; BRABIN, B.J.; OMARI, A.A.A. Food prepared in iron cooking pots as an intervention for reducing iron deficiency anemia in developing countries: a systematic review. J. Human Nutrit. Dietetic, v.16, p.275-281, 2003.

47 RANUM, P. Iron fortification of cereals. In: HURRELL, R. (Ed.). Mineral fortification of foods. Leatherhead, UK: Leatherhead, 1999. p. 251.

48 RANUM, P. Zinc enrichment of cereal staples. Food and Nutrition Bulletin, v.22, p. 169-172, 2001.

49 ROSADO, J.L. Zinc and copper: proposed fortification levels and recommended zinc compounds. Journal of Nutrition, v.133, p.2985S-2989S, 2003.

50 SALGUERIO, M. et al. Fortification strategies to combat zinc and iron deficiency. Nutrition Review, v.60, p. 52-58, 2002.

51 SANDSTROM, B. Micronutrient interactions: effects on absorption and bioavailability. The British Journal of Nutrition, v.85, p.181-185, 2001.

52 SANTOS, L.M.P.; PEREIRA, M.Z. Efeito da fortificação com ácido fólico na redução dos defeitos do tubo neural. Cadernos de Saúde Publica, v.23, n.1, p.17-24, 2007.

53 SHRESTHA, A.K.; ARCOT, J.; PATERSON, J.L. Edible coating materials -their properties and use in the fortification of rice with folic acid. Food Research International, v.36, p.921-928, 2003.

54 STANNER, S. Metal matters: a conference on iron, copper and zinc. Nutrition Bulletin, v.28, p.215-220, 2003.

55 SWAIN, J.H.; NEWMAN, S.M.; HUNT, J.R. Bioavailability of elemental iron powders to rats is less than bakery-grade ferrous sulfate and predicted by iron solubility and particle surface area. Journal of Nutrition, v.133, p.3546S-3552S, 2003.

56 TORRES, M.A.A.; SATO, K.; LOBO, N.F.; QUEIROZ, S.S. Fortificação do leite fluido na prevenção e tratamento da anemia carencial ferropriva em crianças menores de 4 anos. Revista de Saúde Pública, v.30, p.350-357, 1996.

57 TORÚN, B. Fortificación y enriquecimiento de alimentos: consideraciones sobre su uso para alcanzar las metas nutricionales. Archivos Latinoamericanos de Nutrición, v.38, p. 647-655, 1988.

58 UNDERWOOD, B.A. Scientific research: essential, but is it enough to combat world food insecurities? Journal of Nutrition, v.133, p.1434S-1437S, 2003.

59 VISIOLI, F.; HAGEN, T.M. Nutritional strategies for healthy cardiovascular aging: focus on micronutrients. Pharmaceutical Research, v.55, p.199-206, 2007.

60 VITERI, F.E. et al. Fortification of sugar with iron sodium ethylenediaminetetracetate (FeNaEDTA) improves iron status in semirural Guatemalan populations. The American Journal of Clinical Nutrition, v.61, p.153-163, 1995.

61 WAHLQVIST, M.L. National food fortification: a dialogue with reference to Asia: policy in evolution. Asia Pacific Journal of Clinical Nutrition, v.17, p.24-29, 2008.

62 WEGMÜLLER, R.; ZIMMERMANN, M.B.; HURRELL, R.F. Dual fortification of salt with iodine and encapsulated iron compounds: stability and acceptability testing in Morocco and Cote d'Ivoire. Journal of Food Science, v.68, p.21292135, 2003.

63 ZANCUL, M.S. Fortificação de alimentos com ferro e vitamina A. Medicina, v.37, p.45-50, 2004. 